\title{
Progress In Developing Finite Element Models Replicating Flexural Graphite Testing
}

Robert Bratton

The INL is a

U.S. Department of Energy National Laboratory

operated by

Battelle Energy Alliance

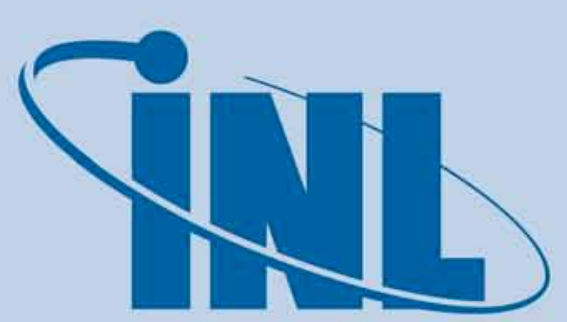

Idaho National Laboratory

June 2010

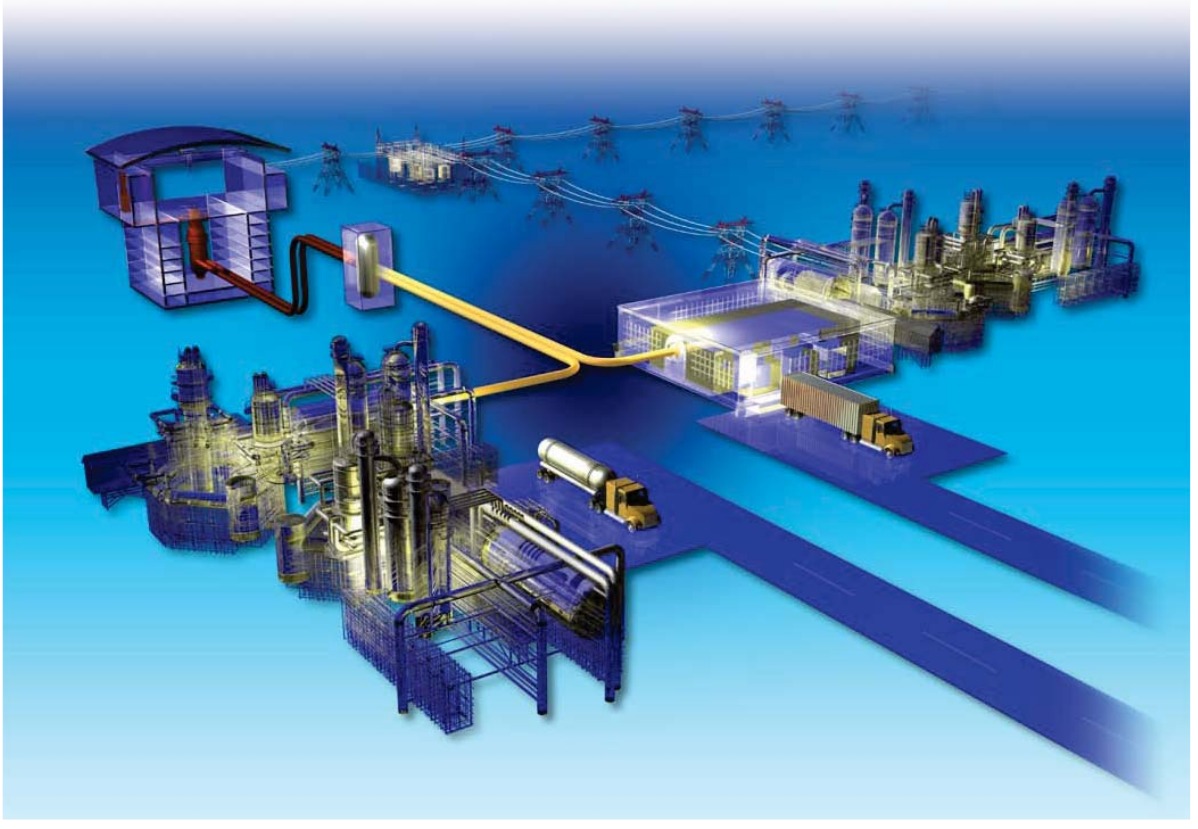




\section{DISCLAIMER}

This information was prepared as an account of work sponsored by an agency of the U.S. Government. Neither the U.S. Government nor any agency thereof, nor any of their employees, makes any warranty, expressed or implied, or assumes any legal liability or responsibility for the accuracy, completeness, or usefulness, of any information, apparatus, product, or process disclosed, or represents that its use would not infringe privately owned rights. References herein to any specific commercial product, process, or service by trade name, trade mark, manufacturer, or otherwise, does not necessarily constitute or imply its endorsement, recommendation, or favoring by the U.S. Government or any agency thereof. The views and opinions of authors expressed herein do not necessarily state or reflect those of the U.S. Government or any agency thereof. 


\title{
Progress in Developing Finite Element Models Replicating Flexural Graphite Testing
}

\author{
Robert Bratton
}

June 2010

\author{
Idaho National Laboratory \\ Next Generation Nuclear Plant Project \\ Idaho Falls, Idaho 83415
}

http://www.inl.gov

Prepared for the

U.S. Department of Energy

Office of Nuclear Energy

Under DOE Idaho Operations Office

Contract DE-AC07-05ID14517 

Next Generation Nuclear Plant Project

\section{Progress In Developing Finite Element Models Replicating Flexural Graphite Testing}

INL/EXT-10-18882

June 2010

Approved by:

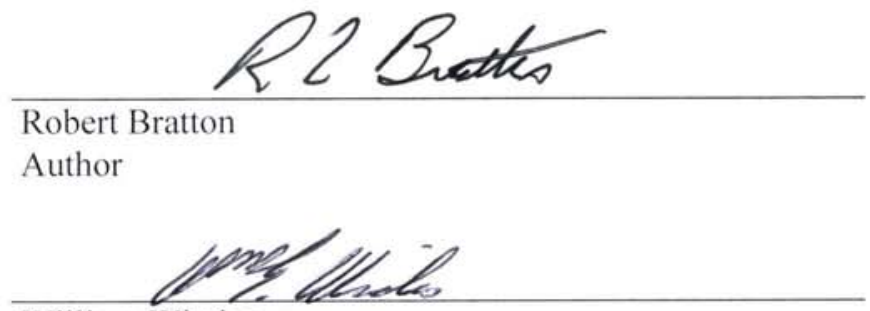

William Windes

VHTR Graphite Lead

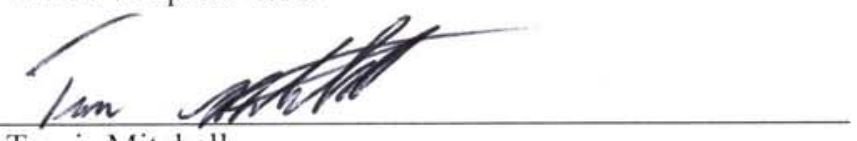

Travis Mitchell

VHTR Project Manager
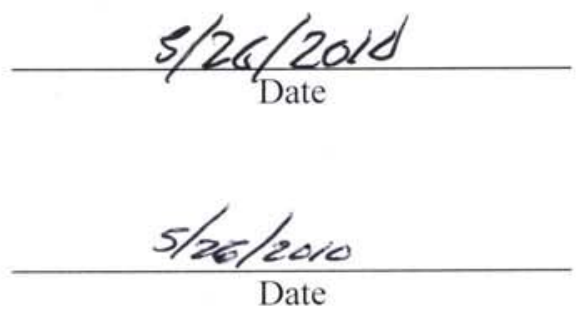

$5 / 26 / 2010$

Date 



\begin{abstract}
This report documents the status of flexural strength evaluations from current ASTM procedures and of developing finite element models predicting the probability of failure. This work is covered under QLD REC-00030.

Flexural testing procedures of the American Society for Testing and Materials (ASTM) assume a linear elastic material that has the same moduli for tension and compression. Contrary to this assumption, graphite is known to have different moduli for tension and compression. A finite element model was developed and demonstrated that accounts for the difference in moduli tension and compression.

Brittle materials such as graphite exhibit significant scatter in tensile strength, so probabilistic design approaches must be used when designing components fabricated from brittle materials. ASTM procedures predicting probability of failure in ceramics were compared to methods from the current version of the ASME graphite core components rules predicting probability of failure. Using the ASTM procedures yields failure curves at lower applied forces than the ASME rules.

A journal paper was published in the Journal of Nuclear Engineering and Design exploring the statistical models of fracture in graphite.
\end{abstract}




\section{CONTENTS}

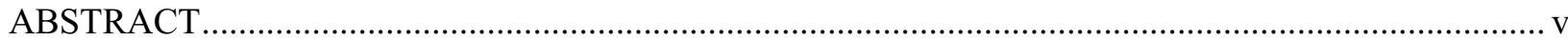

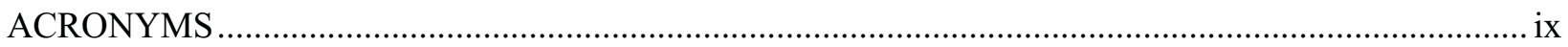

1. FINITE ELEMENT MODELING OF GRAPHITE FLEXURAL TESTING …............................ 1

1.1 Bimodulus Graphite Properties ................................................................................. 1

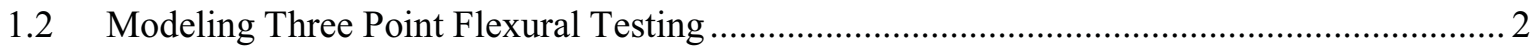

1.3 Modeling Four Point Flexural Testing ...................................................................... 5

2. PROBABILISTIC DESIGN - DETERMINATION OF PROBABILITY OF FAILURE ................9

2.1 Use and Determination of Effective Volumes in Probability of Failure Calculations ............ 9

2.2 Influence of Effective Stress on Effective Volume Value ................................................... 14

2.3 Comparison of POF Values Using ASTM and ASME Rules .......................................... 15

3. NUCLEAR ENGINEER AND DESIGN PAPER ON STATISTICAL MODELS FOR

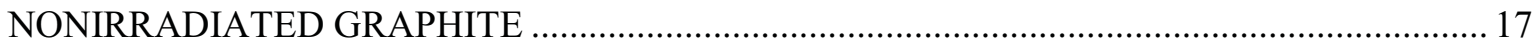

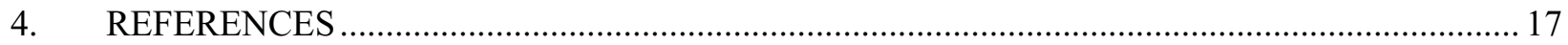

\section{FIGURES}

Figure 1. H-451 stress-strain curves determined from destructive testing............................................. 1

Figure 2. NBG-18 stress-strain curves determined from destructive testing. .......................................... 2

Figure 3. Shift of neutral axis due to unequal modulus in tension and compression................................. 2

Figure 4. Portion of beam in tension or compression depending on the modulus ratio.............................. 3

Figure 5. Comparison of analytical load displacement curve and results from finite element modeling for a three point bend test..................................................................................

Figure 6. Three point bend finite element model.............................................................................. 4

Figure 7. Finite element determined bending stresses at the midpoint for three point bend fixture............ 5

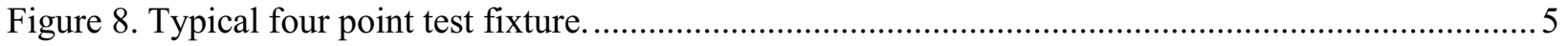

Figure 9. shows the layout of the finite element model. Only half of the model is analyzed due to

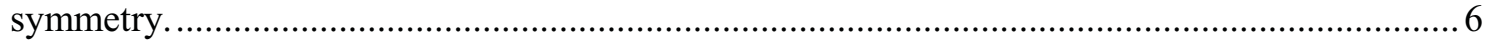

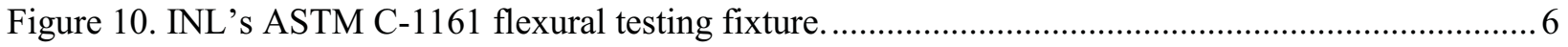

Figure 11. Finite element model of the four point flexural fixture modeling only half of the

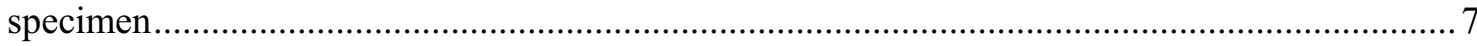

Figure 12. Results of the finite element model showing bending stresses. Blue is for compression and red is for tensile stresses. The black line is the neutral axis. ............................................

Figure 13. Measured flexural data plotted against linear elastic finite element model for graphite Grade Q.

Figure 14. Results of the flexural testing of Grade Q plotted against the predicted results from the bimodulus finite element model. 
Figure 15. Sketch of the flat notched tensile bar used in the effective volume calculations.

Figure 16. Effective volume for a notched tensile bare with a radius of $20 \mathrm{~mm}$.

Figure 17. Comparison between COMSOL and ANSYS on the notched tensile bar performed by Connecticut Reserve Technologies using ANSYS and COMSOL.

Figure 18. COMSOL after cycles of adaptive meshing at the stress concentration................................. 12

Figure 19. Figure 7 from the journal paper by Brücker-Foit. ............................................................. 13

Figure 20. Figure 8 from the journal paper by Brücker-Foit. .......................................................... 13

Figure 21. Effective volume as a function of Weibull modulus using both PIA and MSE stress measures.

Figure 22. POF calculation for the notch tensile bar $(\mathrm{r}=20 \mathrm{~mm})$ as a function of applied load on the bar. 16

Figure 23. POF calculation as a function of the applied load on the notched tensile bar. 16 


\section{ACRONYMS}

ASTM American Society of Testing Materials

NASA National Aeronautics and Space Administration

COMSOL Commercial finite element program from Comsol Inc.

PIA Principle of Independent Action

POF Probability of Failure

CARES Ceramic Analysis and Reliability Evaluation of Structures computer program evaluating probability of failure from finite element program output

MSE Maximum Strain Energy 


\section{Progress In Developing Finite Element Models Replicating Flexural Graphite Testing}

\section{FINITE ELEMENT MODELING OF GRAPHITE FLEXURAL TESTING}

Destructive mechanical testing uses load frames and jigs to stress graphite specimens in different configurations to determine mechanical properties. The flexural strength is the stress at which a slender bar fails with a bending moment applied by a three or four point fixture. The American Society for Testing and Materials (ASTM) standards provide equations using the measured failure data to calculate the flexural strength based on an isotropic linear elastic material. ASTM uses a single tensile modulus in its derivation of equations to obtain the flexural strength.

\subsection{Bimodulus Graphite Properties}

Graphite moduli differ in tension and compression from the majority of materials that normally have the same linear elastic moduli. Graphite stress-strain curves are different in tension and compression. This material behavior deviates from the material model assumed in ASTM standards. Figures 1 and 2 show the nonlinear stress-strain relationship for H-451 and NBG-18. The curves are denoted as polyconvex and exhibit strain softening. Linear elastic stress-strain relationships are represented by a constant Young's modulus until a yield stress is reached where the material plastically deforms or yields with hardening or softening behaviors. The graphite curves show an immediate nonlinearity stress/strain relationship starting from the origin. This has consequences for the analysis of three and four point bend specimens since different stress-strain relationships must be used whether the bulk material is in tension or compression. The data for $\mathrm{H}-451$ is taken from GA documents and NBG-18 is taken from ORNL reports.

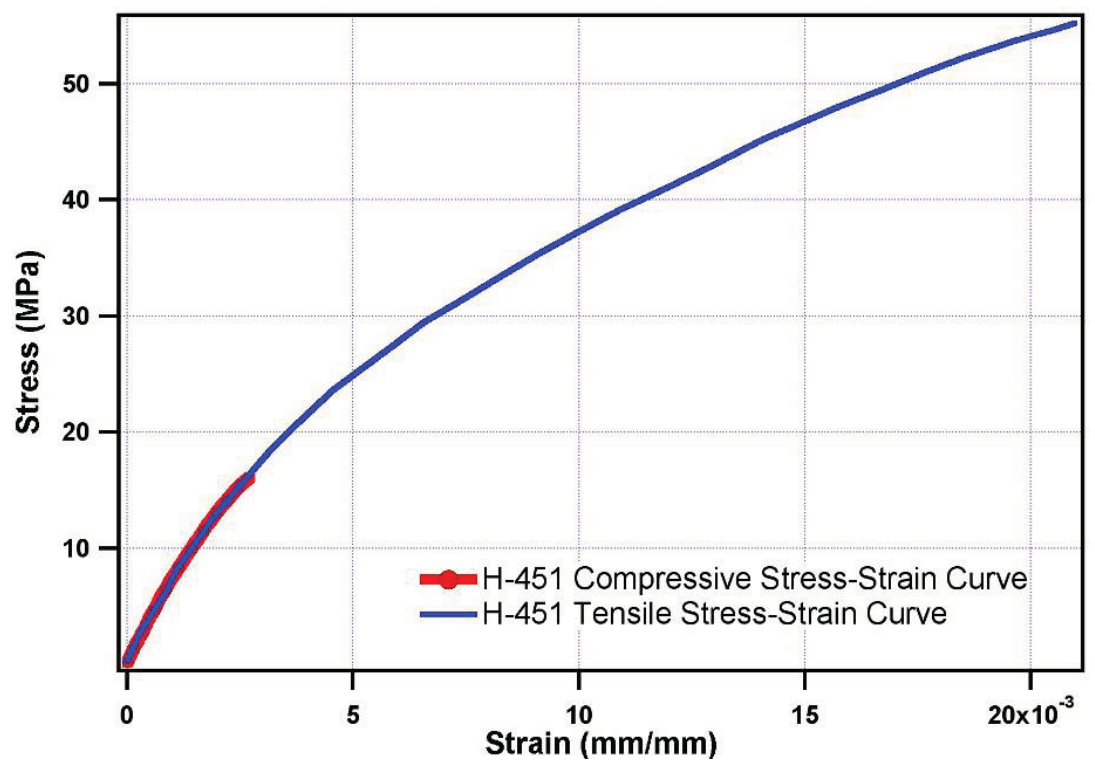

Figure 1. H-451 stress-strain curves determined from destructive testing. 


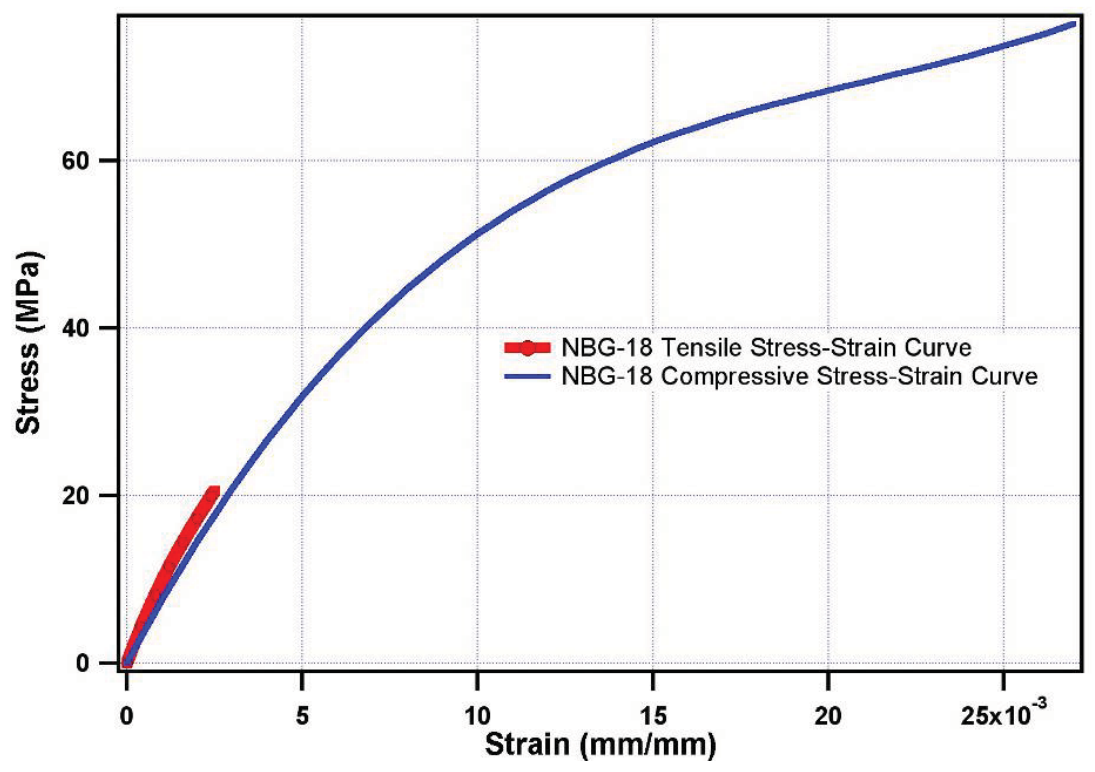

Figure 2. NBG-18 stress-strain curves determined from destructive testing.

The ASTM test procedures will produce the correct data but not the correct flexural strength based on the equations in the standard. Finite element models were built to account for the different moduli in graphite in the flexural test. No material models have been implemented in finite element codes at this time to address the nonlinearity of the stress-strain curves. A Nuclear Energy University Program (NEUP) project is currently developing a mathematical model that takes into account the unique nonlinearity of graphite and will implement the model in the COMSOL (Commercial finite element program from Comsol Inc.) finite element program. All analyses on flexural testing will only use linear elastic (Hookean) material with different moduli in tension and compression. The term bimodulus is used to describe a linear elastic material with different moduli in tension and compression.

\subsection{Modeling Three Point Flexural Testing}

The three point flexural test is used for ASTM testing to determine the fracture toughness of many materials, including graphite. An analytical model for the three point test, assuming bimodulus material, was developed by the National Aeronautics and Space Administration (NASA). The NASA ${ }^{1}$ report contains analytical derivation of the displacement of the neutral axis from its linear isotropic position. Displacement of the neutral axis is also found in the four point bend tests. For a linear elastic isotropic beam in bending, the neutral axis is a hypothetical line demarking that half of the beam is in compression and the other half is in tension. Unequal modulus for tension and compression causes the beam to experience a shift in the neutral axis. The ratio of the two moduli is related to the shift of the neutral axis changing the regions of the beam experiencing tension or compression. The shifted neutral axis is shown in Figure 3 as the dashed red line.

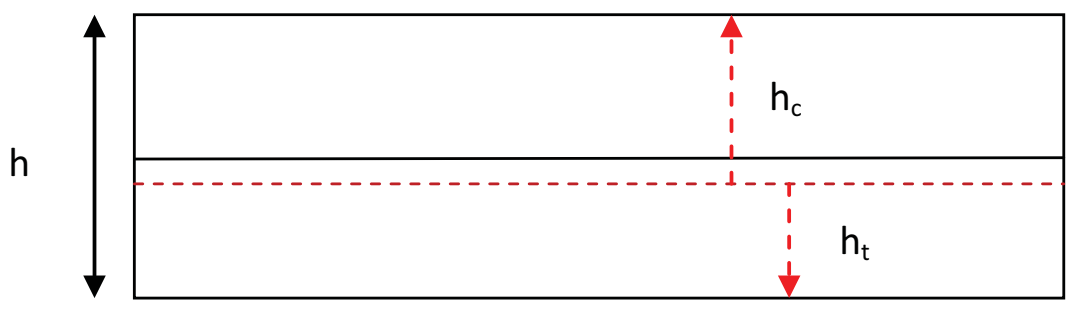

Figure 3. Shift of neutral axis due to unequal modulus in tension and compression. 
The following equation calculates the fractional height of the beam, $\mathrm{h}_{\mathrm{c}}$, in compression:

$\frac{\mathrm{h}_{\mathrm{c}}}{\mathrm{h}}=\frac{1}{\left[1+\left(\frac{\mathrm{E}_{\mathrm{T}}}{\mathrm{E}_{\mathrm{C}}}\right)^{1 / 2}\right]}$

where $h=h_{c}+h_{t}$, and $E_{T}$ and $E_{C}$ are the elastic modulus for tension and compression. Figure 4 shows the fraction of the beam height experiencing tension and compression as a function of the ratio of moduli $\left(\mathrm{E}_{\mathrm{T}} / \mathrm{E}_{\mathrm{C}}\right)$.

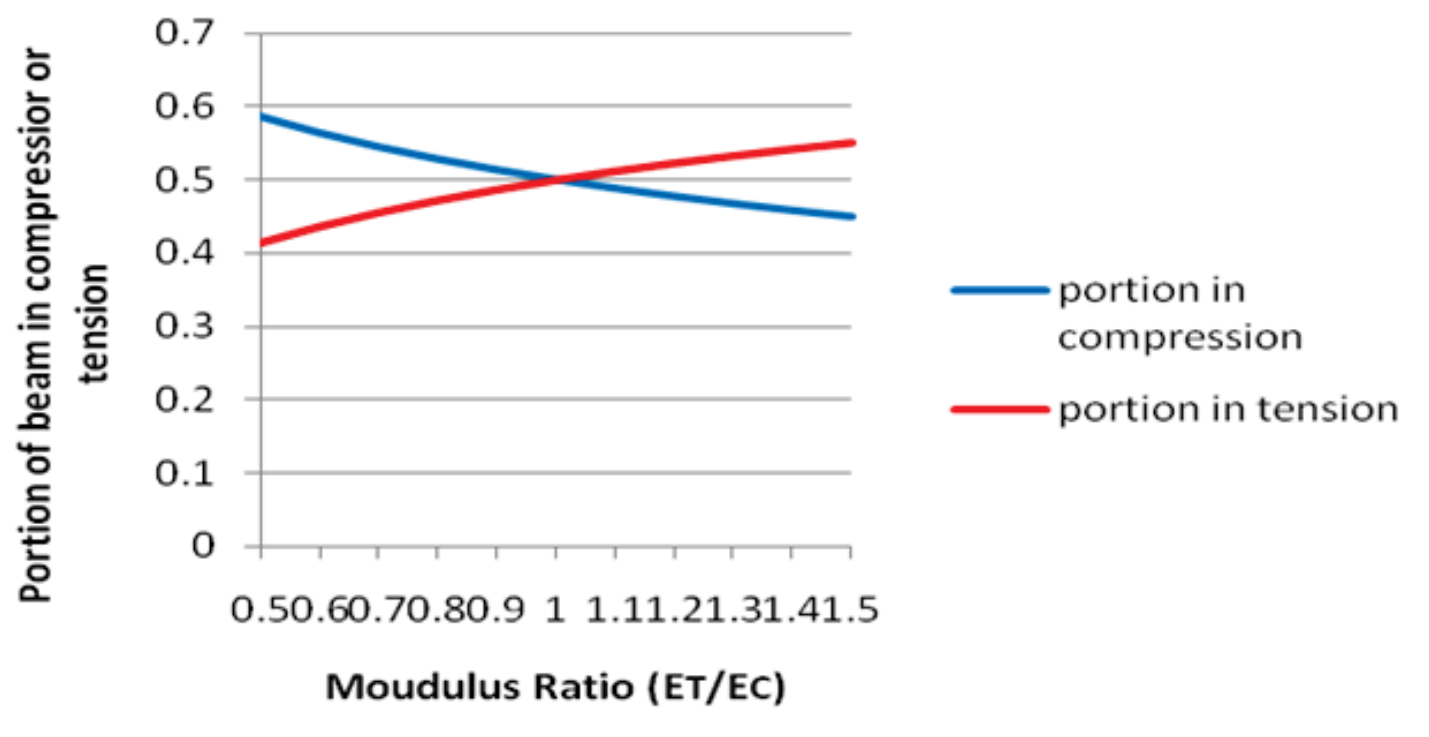

Figure 4. Portion of beam in tension or compression depending on the modulus ratio.

The NASA document also derives the load displacement curve for a load applied at the midspan between the two supports. This expression relates the deflection of the beam's top face versus the applied load. The expression can be found in NASA's report but is not reproduced here because of its algebraic complexity. A COMSOL finite element model was constructed for the three point bend specimen. Figure 5 shows the load displacement curve determined by the COMSOL model overlaid on the analytical load displacement curve calculated from the NASA report. The three point bending finite element model used to determine the load displacement curve is shown in Figure 6. Only half of the three point fixture is modeled because of symmetry. 


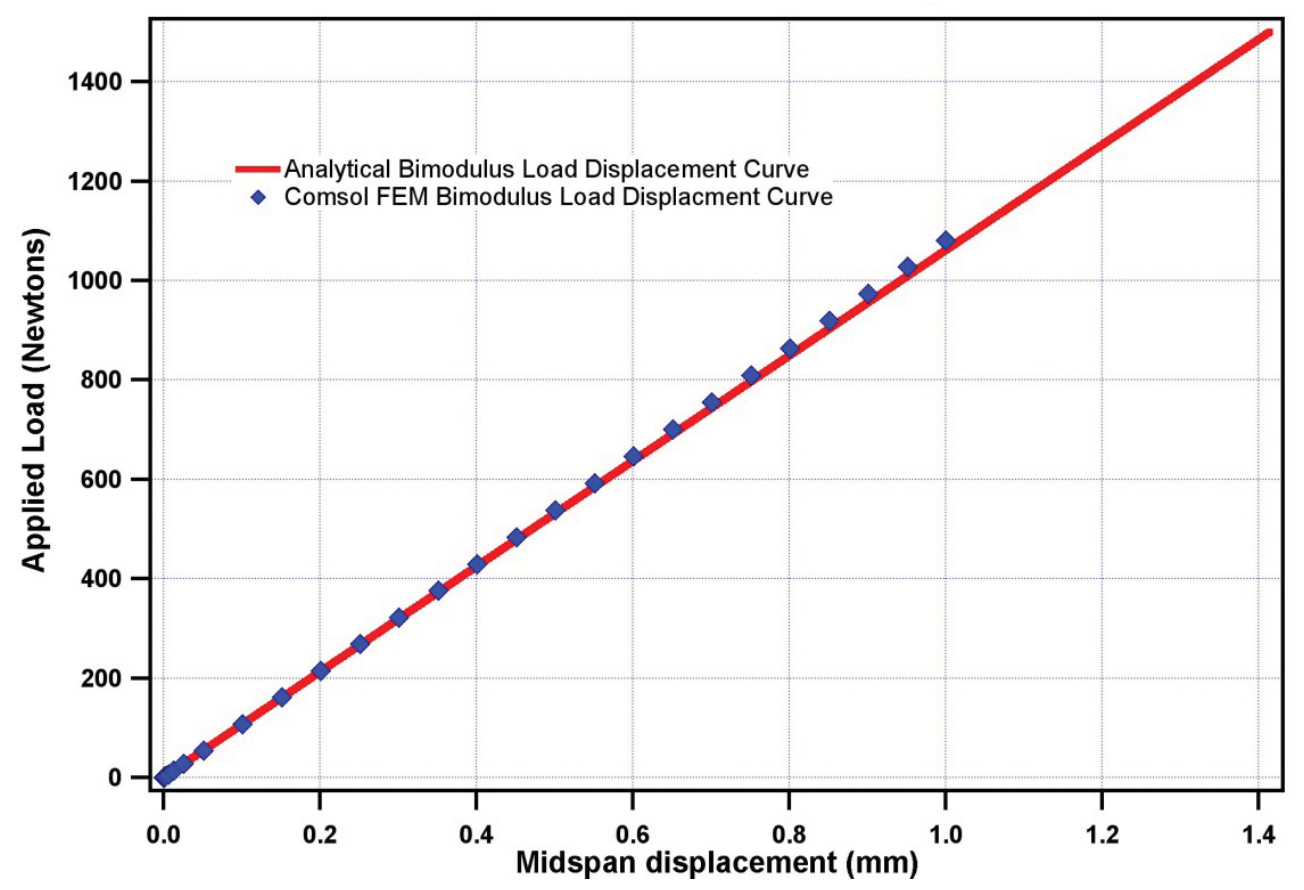

Figure 5. Comparison of analytical load displacement curve and results from finite element modeling for a three point bend test.

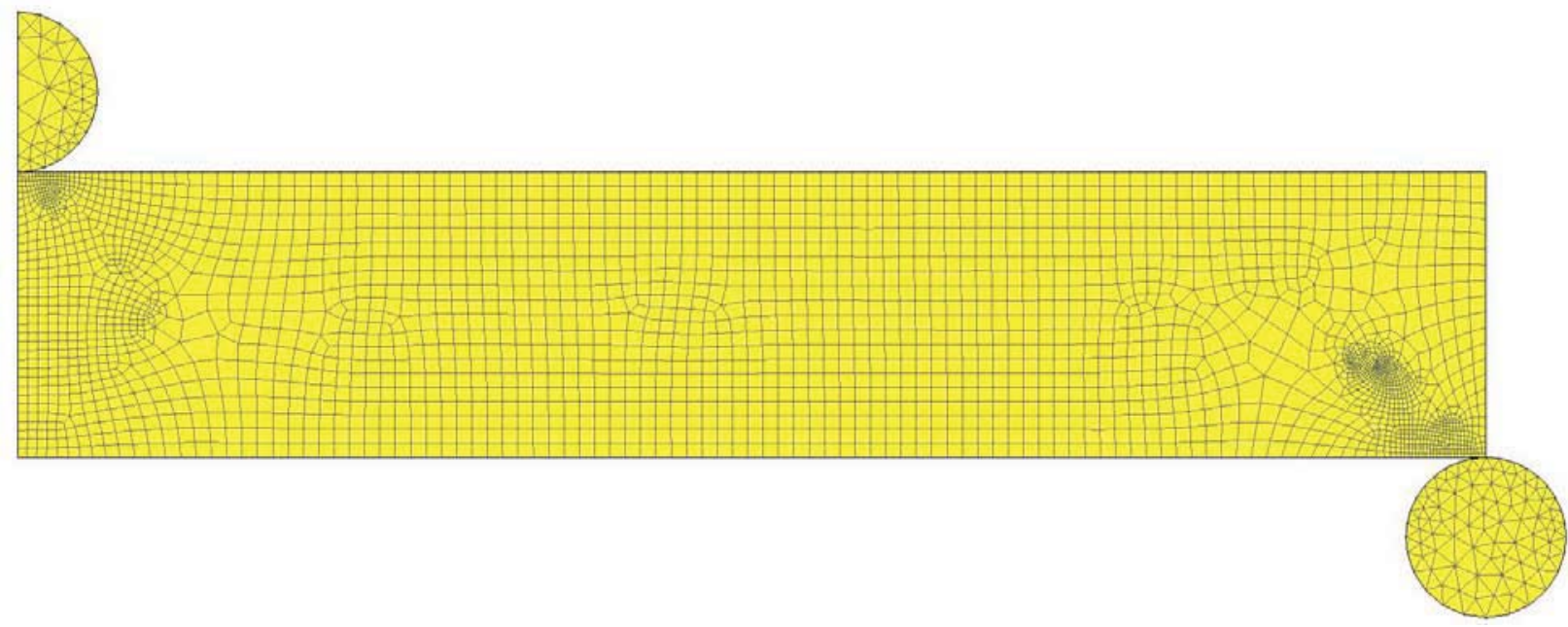

Figure 6. Three point bend finite element model.

The bending stress determined by the COMSOL finite element model at the midspan (left side of Figure 6) is shown in Figure 7. The large blue square (right side) and blue circle (left side) in Figure 7 is the maximum tensile and compressive stresses predicted by the analytical equations in the NASA report. The black line in the middle of the figure is the shifted neutral axis calculated by Equation 1. The beam height, $\mathrm{h}$, is from -8 to $8 \mathrm{~mm}$ with zero located at the midsection of the beam. Beyond $8 \mathrm{~mm}$ is the bending stress in the roller applying the displacement. The compressive bending stress does not intersect the blue square because of the presence of Hertzian contact stresses in the specimen. 


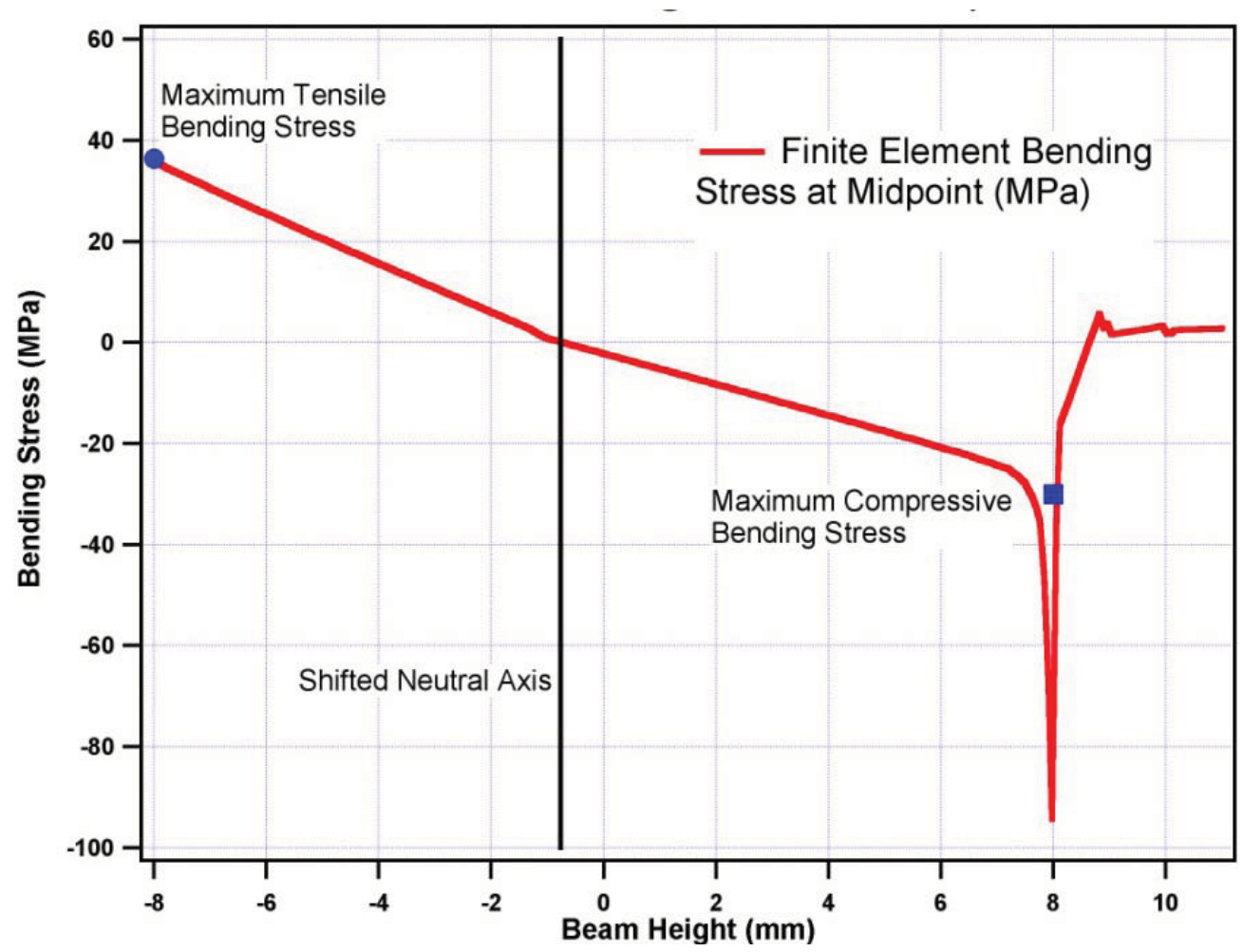

Figure 7. Finite element determined bending stresses at the midpoint for three point bend fixture.

Two points are worthy of note from the NASA report:

1. Assuming a linear isotropic material for a bimodulus material underestimates the flexural deflection by $25 \%$ at a ratio (ET/EC) of 1.5 and overestimates flexural deflection by $25 \%$ at a ratio (ET/EC) of 0.5 .

2. The beam's length-to-height ratio has negligible effect on the flexural deflection when the ratio is greater than 10 in the modulus ratio range of $0.5 \leq(\mathrm{ET} / \mathrm{EC}) \geq 2.0$.

\subsection{Modeling Four Point Flexural Testing}

Four point flexural testing creates two opposing moments on either side of the specimen's centerline creating a constant bending stress between the applied moments. The flexural strength is the maximum stress on the outer fibers at the point of maximum force. The maximum bending stress occurs on the bottom face just in front of the top roller. Figure 8 shows a typical four point flexural setup where the load is applied at two points on the top of the specimen by rollers and support loads are supplied by two rollers on the bottom of the specimen located outside the two top rollers. The fixture is symmetric about the middle of the specimen so only half of the test fixture is modeled as show in Figure 9.

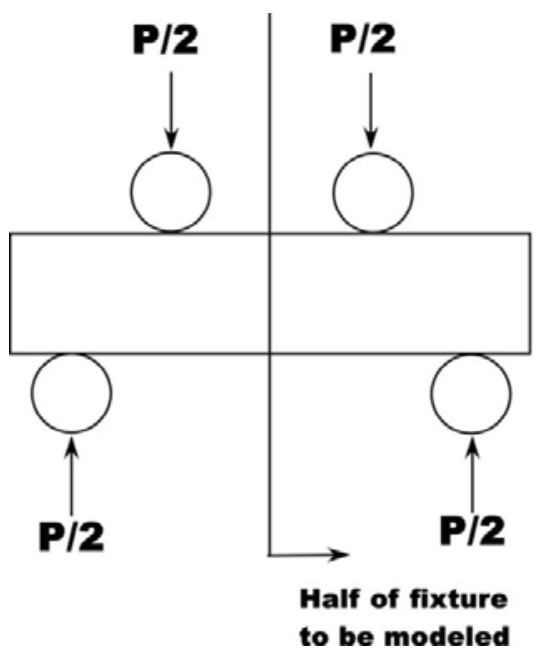

Figure 8. Typical four point test fixture. 


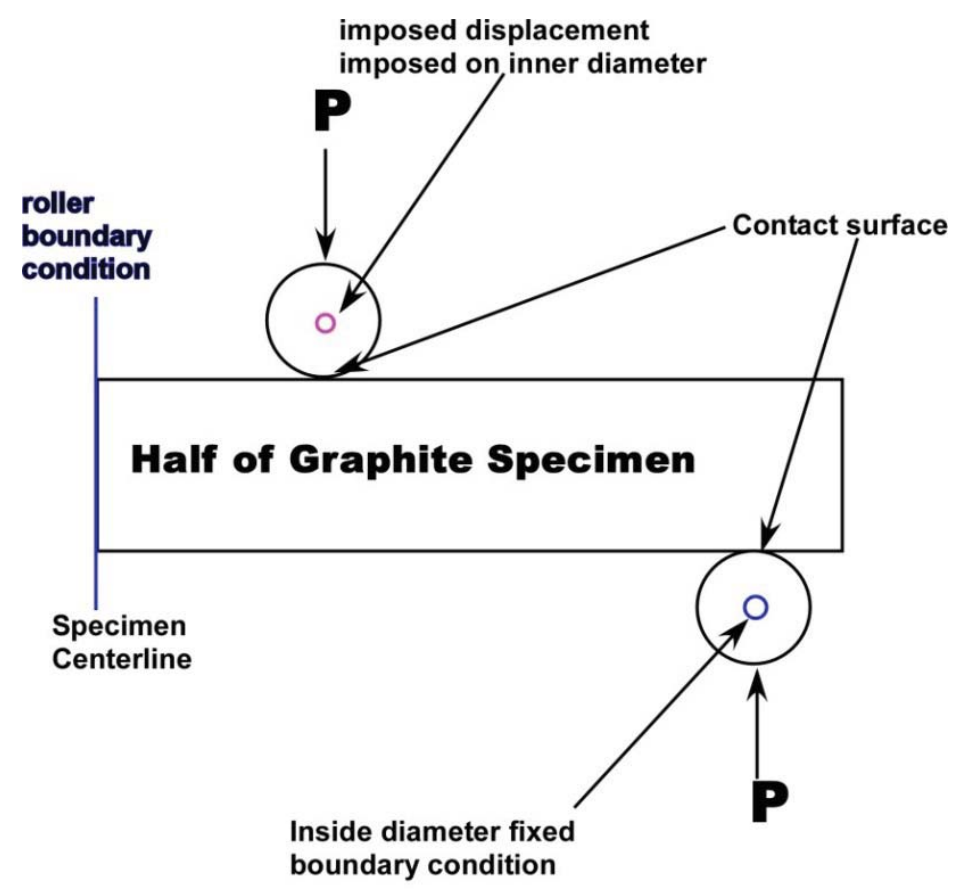

Figure 9. shows the layout of the finite element model. Only half of the model is analyzed due to symmetry.

INL has purchase a flexural fixture shown in Figure 10. The fixture is scaled up from the one in the picture to accommodate the size of the specimens (6.5 in. long, $0.63 \mathrm{in}$. high, and $1.25 \mathrm{in}$. wide). Rollers are allowed to rotate in the fixture, but translation is restricted. The displacement is applied to each individual roller. The only contact forces present are the rollers touching the specimen thus the finite element model for this fixture has less complexity. The ram of the load frame imparts a monotonic force of $\mathrm{P}$ on the fixture and each of the top rollers applies a force of $\mathrm{P} / 2$ on the specimen. The bottom rollers support the specimen creating the moment or bending action in the middle of the specimen. All four rollers are free to rotate about their own axis and are restrained from lateral movement by the fixture. ASTM has four axioms or assumptions used in the derivation of bending stresses. These assumptions are also the same in basic beam theory:

1. Transverse plans perpendicular to the longitudinal axis of the beam remain plain after the beam is bent.

2. The modulus of the elasticity in tension is equal to the modulus of elasticity in compression; the beam material is isotropic and homogeneous.

3. The maximum deflection must be small compared to the beam depth.

4. The beam must deflect normally under elastic bending stresses but not through any local collapse or twisting.

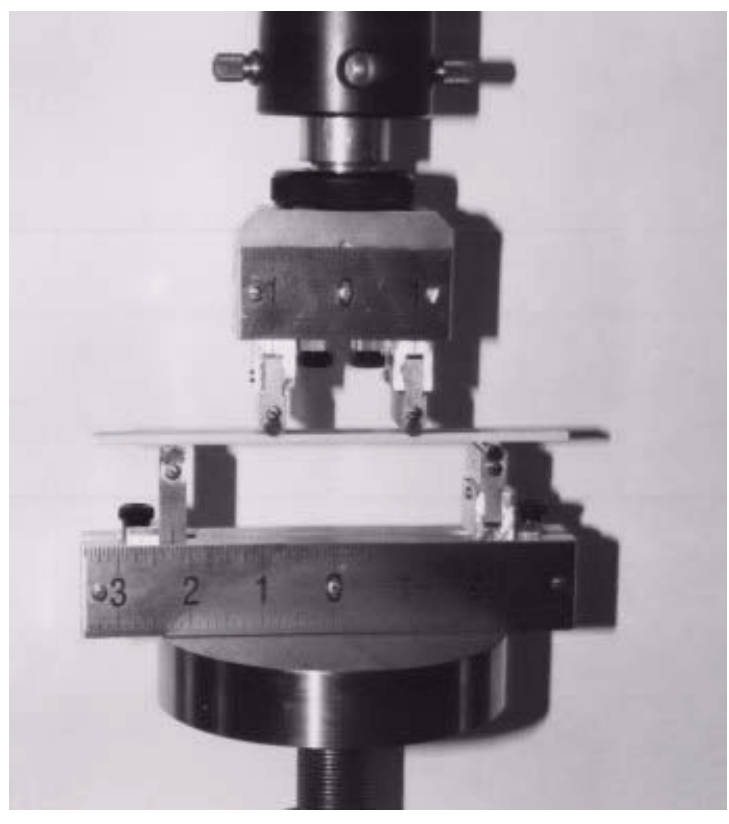

Figure 10. INL's ASTM C-1161 flexural testing fixture. 
The first assumption is valid if the flexure could be obtained without applications of local forces, such as, friction between the rollers and specimen and applied contact forces of the rollers creating compressive stresses in the region contact surrounding the roller. The second assumption is not valid for graphite, since the modulus for tension and compression are different for graphite. The second assumption is also not valid since graphite is nonlinear elastic orthotropic material and not linear elastic isotropic. The third assumption is valid if the deflection is less than $10 \%$ of the beam depth. The fourth assumption is valid so long as the graphite is not modeled as an orthotropic material. The COMSOL mesh of fixture is shown in Figure 11.

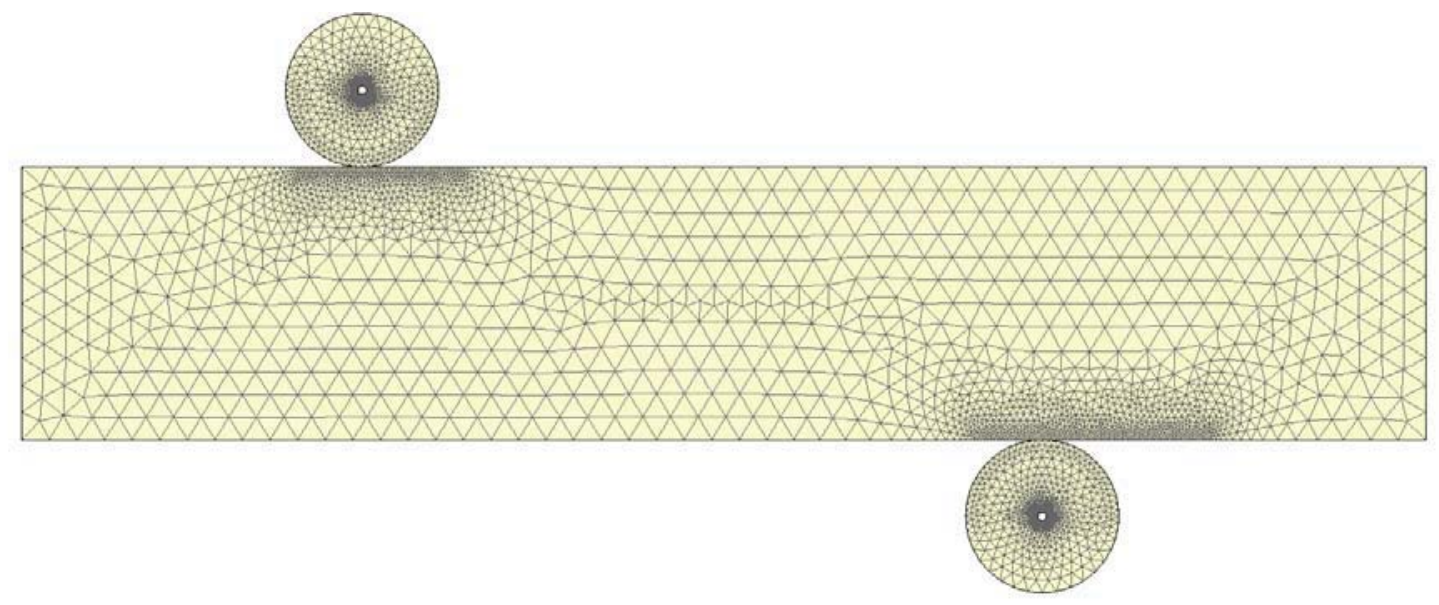

Figure 11. Finite element model of the four point flexural fixture modeling only half of the specimen

The symmetry axis is the left side of the model. An applied displacement is imposed on the top roller. The bottom roller is fixed supporting the bar. As the imposed displacement is increased, the graphite bar bends creating a state of tensile stress on the bottom and a compressive stress on the top. Between the two stress states is the neutral axis that has a stress state of zero. In Figure 12, the color in the bar represents the tensile and compressive bending stress. Blue is a compressive stress state and red is the tensile stress state. The colors gradually turn to green representing a zero bending stress. The black contour line is the neutral axis. The white arrows are the principle stresses. Arrow heads pointing outward are tensile and inward pointing arrow heads are compressive stresses.

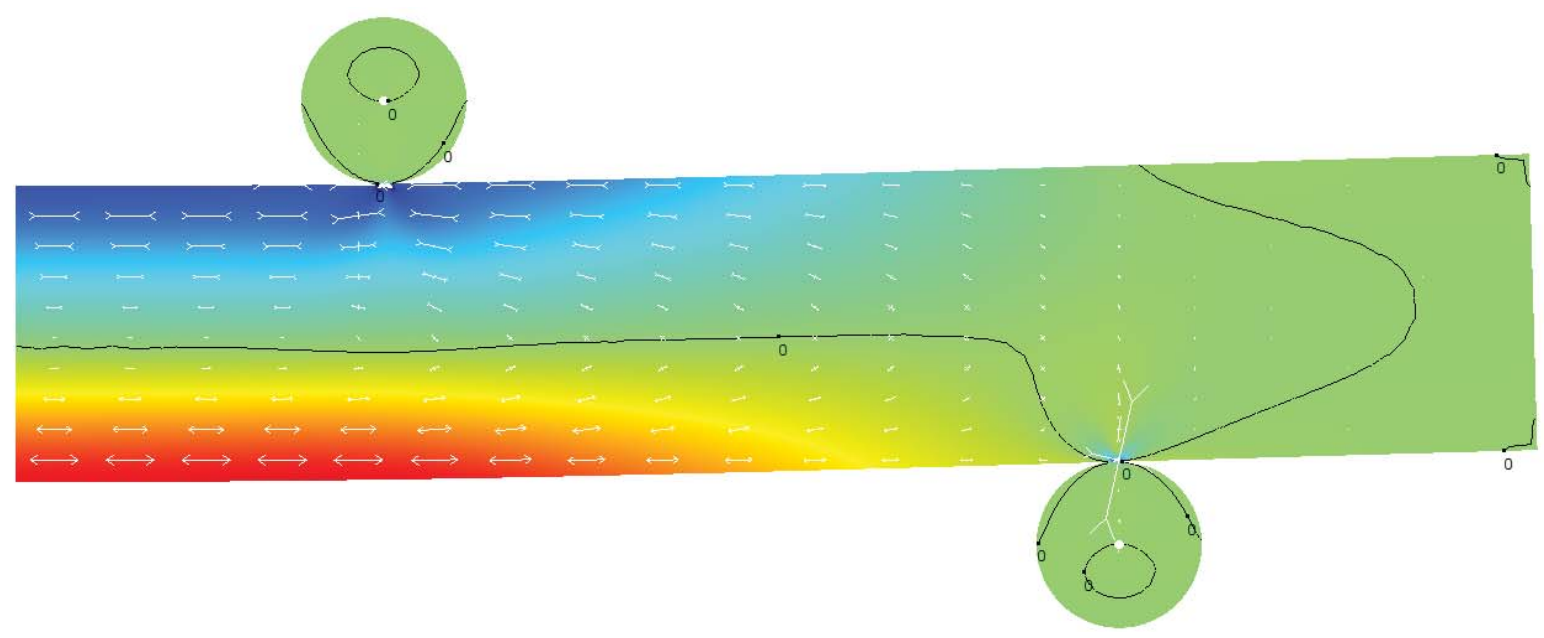

Figure 12. Results of the finite element model showing bending stresses. Blue is for compression and red is for tensile stresses. The black line is the neutral axis. 
To check the validity of the model results of graphite, Grade Q was tested in the four point fixture. A load displacement curve measured from the applied load is plotted against the measured midpoint deflection, which is measured at the bottom left hand corner in Figure 12. Figure 13 shows the measure results plotted against the results of the finite element model only using a tensile modulus as required by the ASTM standard.

The three lines of graphite Grade Q represent results from three different bars tested. Figure 14 are the results of the three bars plotted against the finite element model taking into account the different moduli in Grade Q. This model is denoted as the bimodulus model.

Figure 14 shows that a bimodulus model captures the different stress state because of the difference in moduli while the linear model used in Figure 13 does not. The curvature of the measured data is because of graphite's nonlinear elastic model discussed above. The bimodulus model does not account the nonlinear elastic model. This capability will be added to the model in the future.

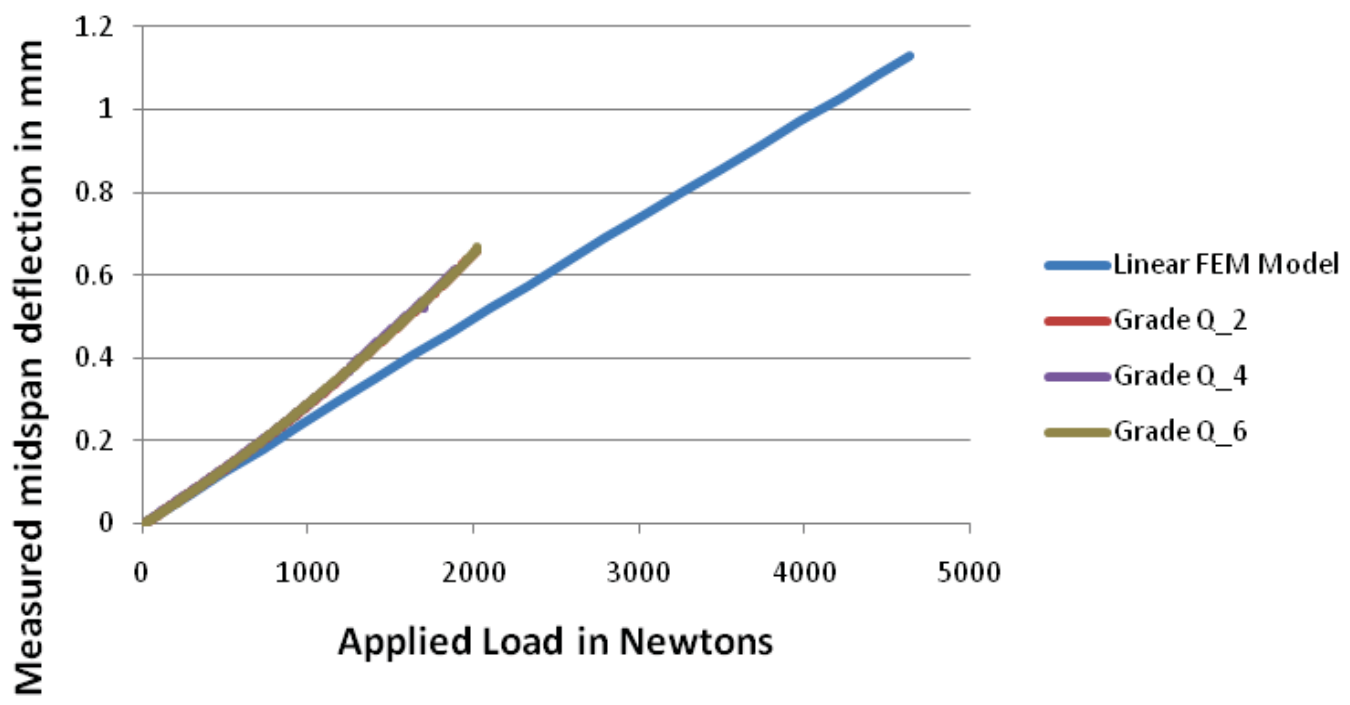

Figure 13. Measured flexural data plotted against linear elastic finite element model for graphite Grade Q.

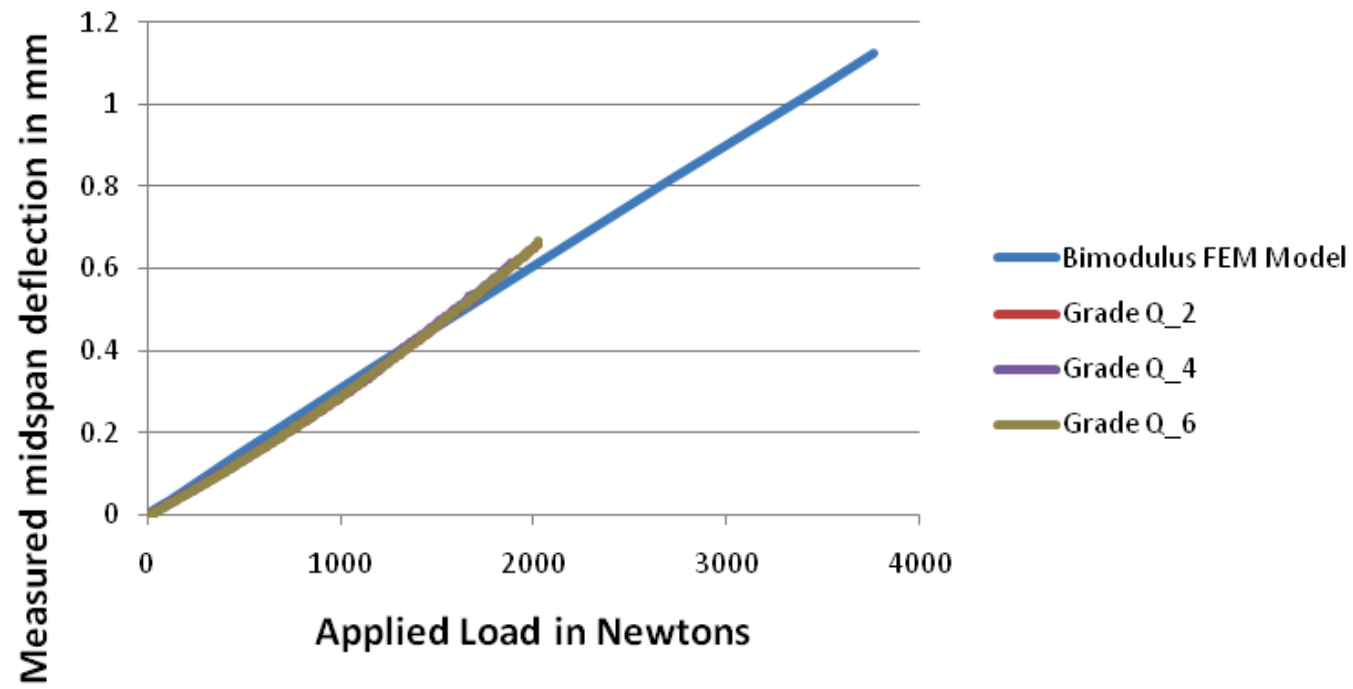

Figure 14. Results of the flexural testing of Grade Q plotted against the predicted results from the bimodulus finite element model. 


\section{PROBABILISTIC DESIGN - DETERMINATION OF PROBABILITY OF FAILURE}

Brittle materials such as graphite exhibit significant scatter in tensile strength, thus probabilistic design approaches must be utilized when designing components fabricated from brittle materials. Accounting for the inherent scatter in tensile strength requires a change in philosophy on the design engineer's part that leads to a reduced focus on the use of safety factors in favor of reliability analyses. If a brittle material with an statistical distribution in tensile strength is selected for its high strength attributes or inert behavior, then components should be designed using an appropriate design methodology rooted in statistical analysis. However, the reliability approach demands that the design engineer must tolerate a finite risk of unacceptable performance. This risk of unacceptable performance is identified as a component's probability of failure (or alternatively, component reliability). The primary concern of the engineer is minimizing this risk in an economical manner.

The techniques of calculating brittle component reliability were not used in previous HTGR design or licensing activities. However, they are accepted in the design of ceramic components in other fields and will be needed for new reactor licensing.

\subsection{Use and Determination of Effective Volumes in Probability of Failure Calculations}

The use of probabilistic determination of survival for ceramics using standard ASTM mechanical test specimens is well established in ASTM standards C-1239 and C-1683. ${ }^{2,3}$ The failure probability for a mechanical test specimen is given by the Weibull cumulative distribution function

$P_{f}=1-\exp \left[-\frac{\sigma_{\max }}{\sigma_{\theta}}\right] \sigma_{\max }>0$

where:

$\mathrm{P}_{\mathrm{f}}$ is the probability of failure

$\sigma_{\max }$ is the maximum tensile stress in a test specimen at failure

$\sigma_{\theta}$ is the Weibull characteristic strength (corresponding to a $P_{f}=0.632$ )

$\mathrm{m}$ is the Weibull modulus determined from testing.

The Weibull characteristic strength is dependent on the test specimen and will change with the test specimen geometry as well as the stress state. If the strength controlling flaws are volume distributed, an alternative formulation of the above expression is

$P_{f}=1-\exp \left[\int_{V}\left(\frac{\sigma}{\left(\sigma_{0}\right)_{V}}\right)^{m} d V\right]$

where $\mathrm{P}_{\mathrm{f}}=0$ when $\sigma \leq 0$.

The term $\left(\sigma_{0}\right)_{\mathrm{V}}$ is called the Weibull material scaled parameter and can be described as the Weibull characteristic strength of a hypothetical test specimen with unit volume loaded in uniform uniaxial tension. For the general case where stress varies with position in the mechanical test specimen and the flaw variation is volume distributed, the integral yields the expression

$P_{f}=1-\exp \left[-k V\left(\frac{\sigma}{\left(\sigma_{0}\right)_{v}}\right)^{m}\right]$ 
where $\left(\sigma_{0}\right)_{V}=\left(\sigma_{\theta}\right)_{V}(k V)^{1 / m}=\left(\sigma_{\theta}\right)_{V} V_{E}^{1 / m}$.

The effective stress at a point in the specimen, $\sigma$, is calculated using an algebraic expressions of the principle stresses. These algebraic expressions are different failure theories assumed for the material. The most general expression is Principle of Independent Action (PIA). The value V is the stress volume and $\mathrm{k}$ is a fitting parameter determined from the experimental data. Today, with finite element software, solving for the effective volume $\mathrm{V}_{\mathrm{E}}$ is a straight forward numerical process. The Weibull characteristic strength $\left(\sigma_{\theta}\right)_{V}$ is a function of specimen geometry and stress gradients while the Weibull scale parameter is a derived material parameter used to compute the probability of failure (POF) of a component based on the strength test from simple test components. Conceptually, one determines $\left(\sigma_{\theta}\right)_{V}$ from simple test configurations such as uniaxial, flexural, or pressurized ring and uses the effective volume integral expression applied to the test specimen to compute $\left(\sigma_{0}\right)_{V}$. In theory, the Weibull scale parameter should be the same from each simple test specimen. Once the Weibull scale parameter is determined, the component POF is calculated using the integral in Equation 3 and the Weibull scale parameter from any of the simple tests. Experimental techniques can cause deviations from theory where the Weibull scale parameter obtained from simple tests are not the same. This means ASTM mechanical test for procedures for graphite must be reviewed and tested to ensure that optimal repeatable techniques are used.

ASTM C 1683 has analytical expressions for $\mathrm{V}_{\mathrm{E}}$ for simple ASTM mechanical test specimen geometries. The standard also has a method that can be used to determine $\mathrm{V}_{\mathrm{E}}$ for mechanical test specimen geometries not covered in the ASTM standard. One such specimen geometry is the doubled notch tensile bar. The geometry of the notched tensile bar is shown in Figure 15. The problem was modeled with two- and three-dimensional (2-D and 3-D) models in COMSOL. The necessary calculations to determined the $\mathrm{V}_{\mathrm{E}}$ where implemented inside the COMSOL model using a PIA model for the effective stress. For comparison, the commercial program CARES was used to predict the effective volume based on the results from the 3-D COMSOL model.

Figure 16 shows the comparison between the 2-D model, 3-D model, and CARES analysis for the notch tensile bar. CARES extracts the data from the output of the 3-D COMSOL model to calculate the effective volume. A comparison was made by Connecticut Reserve Technologies ${ }^{4}$ (CARES developer) using ANSYS on the same tensile bar geometry.

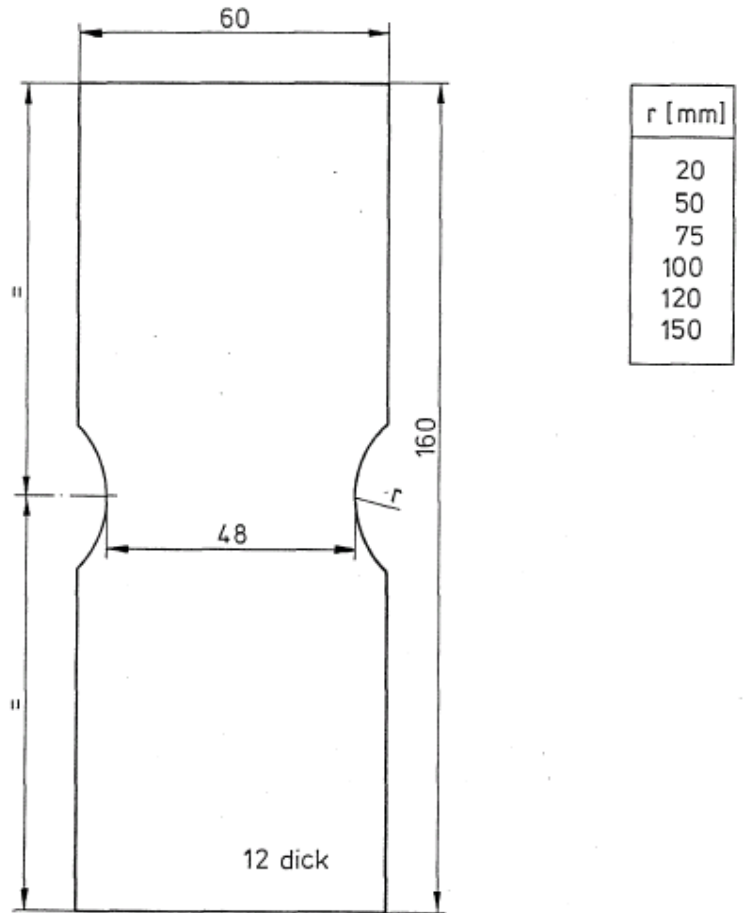

Figure 15. Sketch of the flat notched tensile bar used in the effective volume calculations. 


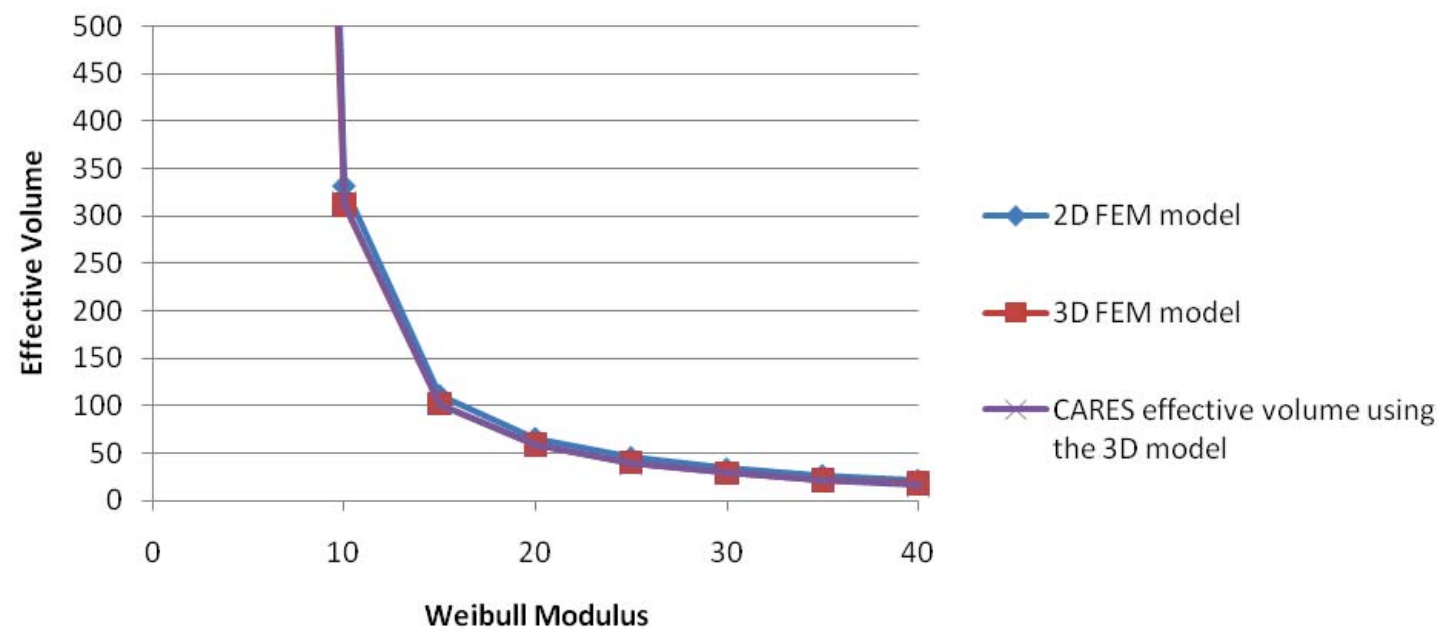

Figure 16. Effective volume for a notched tensile bare with a radius of $20 \mathrm{~mm}$.

Figure 17 shows the results between ANSYS and COMSOL CARES results. In the COMSOL model an adaptive meshing algorithm was used to force refinement of the mesh at the point of peak stress concentration. This provided the best results. If a uniform mesh had been used and the mesh density had increased uniformly, less accurate results would have been obtained. In fact this exercise demonstrated the need for a fine mesh at the point of stress concentration for an accurate determination of the effective volume. Iterative adaptive mesh cycles were employed in COMSOL before the value of the effective volume reached an asymptote. This is the point being made by Connecticut Reserve Technologies in Figure 17. The mesh used in COMSOL is shown in Figure 18.

\begin{tabular}{|l|c|c|c|}
\multicolumn{1}{|c|}{ MODEL } & $\begin{array}{c}\text { Model } \\
\text { Max Stress }\end{array}$ & $\begin{array}{c}\text { CARES } \\
\text { Max Stress }\end{array}$ & $\begin{array}{c}\text { Effective Volume } \\
(m=10.0)\end{array}$ \\
\hline COMSOL Original BC & 41.105 & 40.318 & 319.20 \\
\hline COMSOL Modified BC & 40.269 & 40.215 & 315.77 \\
\hline ANSYS 3D & 40.267 & 40.221 & 315.79 \\
\hline
\end{tabular}

- Model Max Stress is Nodal maximum stress

- CARES Max Stress is Integration Point maximum stress

A measure of the "goodness" of mesh refinements relative to the effective volume or area calculation is the reduction in the difference between the nodal maximum stress and the integration point maximum stress.

Figure 17. Comparison between COMSOL and ANSYS on the notched tensile bar performed by Connecticut Reserve Technologies using ANSYS and COMSOL. 


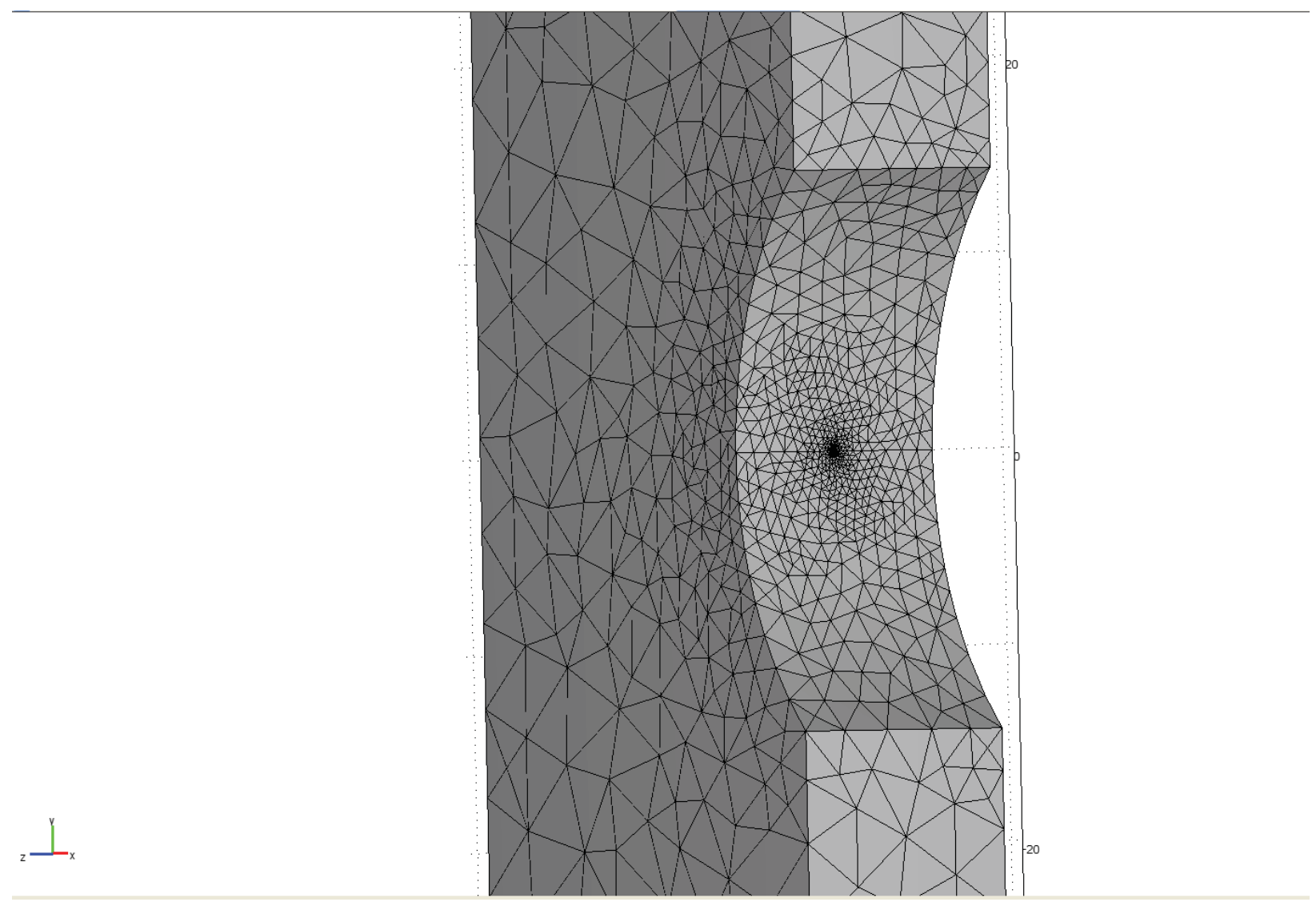

Figure 18. COMSOL after cycles of adaptive meshing at the stress concentration.

The 2-D effective volume calculations in COMSOL used higher order elements and a higher mesh density around the notch than the 3-D calculation. The 3-D model could not use higher order elements because of insufficient memory available on the workstation. There was a difference in the effective volume and peak stresses seen between the 2-D and 3-D models. A 2-D model does not capture the variance of the tensile stresses across the thickness of the bar. To ascertain if the 3-D model has truly reached an asymptotic value for the effective volume, an upgraded workstation must be acquired with more memory. 3-D models of the four point bend test require even higher mesh densities than tensile bar because of the Hertizan contact that be must modeled.

In Figure 16, as the Weibull modulus decreases the scatter in the data increases, thus larger effective volumes must be used. This also shows a need to determine the Weibull modulus of the prospective NGNP graphite accurately since most nuclear graphite have moduli between 5 and 24 . This problem was further studied by Brücker-Foit et al., ${ }^{5}$ for notches of different geometries and different stress concentrations. The researchers looked at the effect of stress concentration on the probability of failure in different regions around the notch. Figure 19 shows the probability of failure in different regions around the notch geometry as a function of Weibull modulus. For the volume of the entire bar, Volume 5, it is preferable to select a material with a Weibull modulus above 8 . If a material with a high Weibull modulus, say above 10, is selected, the area of probability of failure is highest for half of an ellipsoid centered on the apex of the notch. 


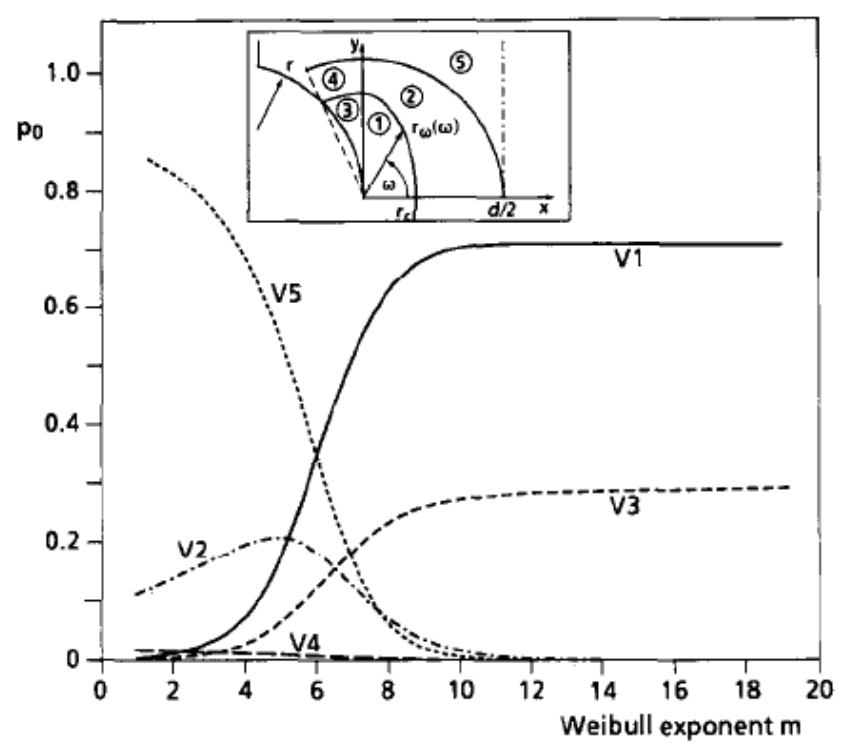

Fig. 7. Local risk of rupture $p_{0}$ for the sub-volumes V1-5; notch N51.

Figure 19. Figure 7 from the journal paper by Brücker-Foit.

Thus for material with a higher Weibull modulus, the potential for a crack to appear in the half ellipsoidal volume next to the apex of the notch may not lead to a failure in the component. Because of crystalline damage due to irradiation in graphite, mechanical properties of graphite change requiring reevaluation of the probability of failure throughout the graphite core's lifetime.

The researchers also looked at the ratio of the stress integral, $\mathrm{H}$, in all five volumes over the stress concentration, $\alpha_{\mathrm{k}}$. The stress integral includes the effects of the Weibull strength distribution. For design, the engineer does not want the stress concentration to exceed the stress integral. This is shown in Figure 20 where, for a chosen notch geometry and corresponding stress concentration, the ratio versus Weibull modulus is plotted. The engineer then looks at this plot to determine the minimum Weibull modulus plus a safety factor the material must have to survive the stress concentration.

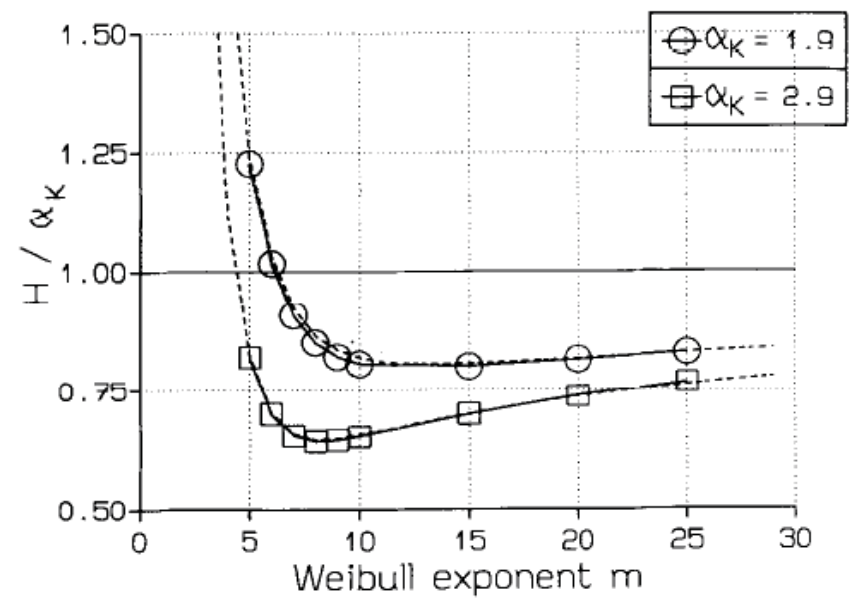

Fig. 8. Comparison of the analytical approximation for $\mathbf{H}$, eqns (28)-(33), with the results of the finite-element analysis; -. - analytical solution; - numerical analysis.

Figure 20. Figure 8 from the journal paper by Brücker-Foit. 


\subsection{Influence of Effective Stress on Effective Volume Value}

The Weibull scale parameter is obtained by calculating the effective volume $\left(\sigma_{0}\right)_{V}=\left(\sigma_{\theta}\right)_{V} V_{E}{ }^{1 / m}$. An intermediate step in obtaining the effective volume is evaluating the integral over the simple test specimen. Equation 5 is the integral performed over the tensile regions of the test specimen in the finite element model.

$V_{E}=\int_{V}\left(\frac{\sigma}{\sigma_{M A X}}\right)^{m_{V}} d V$

The stress $\sigma$ in the integrand is a stress measure used to represent a stress failure surface using the principle stresses in the element. One stress measure commonly used is the PIA, which sums the contribution of each of the three principle stresses $\sigma_{1}, \sigma_{2}$, and $\sigma_{3}$ (tensile stress only). The stress concentration's peak stress in the finite element analysis is assigned to $\sigma_{\mathrm{MAX}}$. The integral for effective volume using PIA in the integrand is

$V_{E}=\int_{V}\left(\frac{\sigma_{1}}{\sigma_{M A X}}\right)^{m_{V}}+\left(\frac{\sigma_{2}}{\sigma_{M A X}}\right)^{m_{V}}+\left(\frac{\sigma_{3}}{\sigma_{M A X}}\right)^{m_{V}} d V$

PIA has no failure theory or fracture geometry associated with its use. It is widely used because of its simplicity in implementation. It is used for static analysis where there is no temperature or fatigue dependence. Another stress measure is the Maximum Strain Energy (MSE), commonly referred to a Von Mises stress. The integral for effective volume using MSE in the integrand is

$V_{E}=\int_{V}\left(\frac{\sigma_{M S E}}{\sigma_{M A X}}\right)^{m_{V}} d V$

where $\sigma_{\mathrm{MSE}}=\left(\sigma_{1}^{2}+\sigma_{2}^{2}+\sigma_{3}^{2}-2 v\left(\sigma_{1} \sigma_{2}+\sigma_{2} \sigma_{3}+\sigma_{1} \sigma_{3}\right)\right)^{0.5}$.

MSE is associated with a known failure theory without a prescribing a crack geometry and has superior representation of multiaxial stress states over PIA. Other stress measures that model actual fracture/crack geometries can be used. Implementation of these requires additional modeling using MATLAB and COMSOL because of the additional stress integration over the hypothetical prescribed crack geometry in each element. These models will be assessed at a later time.

Figure 21 is a plot of the effective volume calculation using both PIA and MSE in the effective volume integral. There is a small difference between the curve for PIA and MSE. 


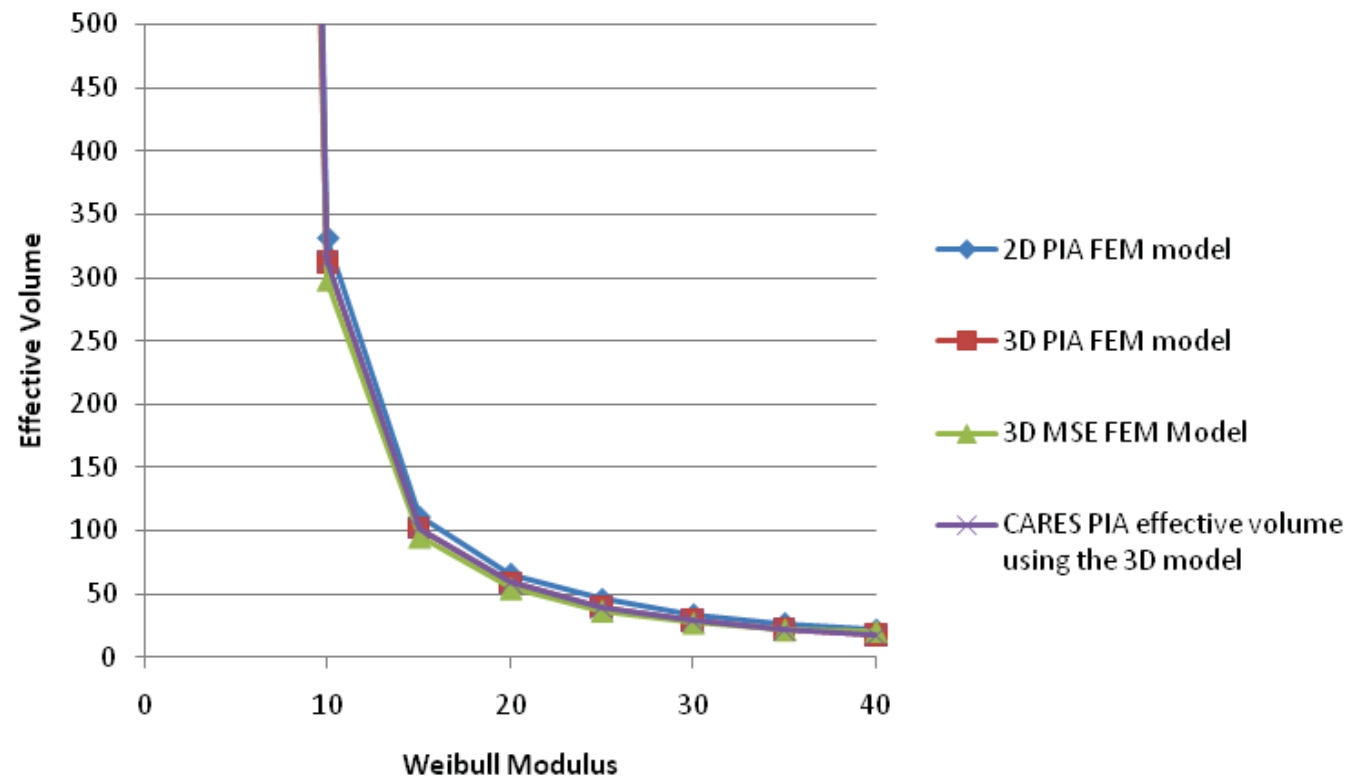

Figure 21. Effective volume as a function of Weibull modulus using both PIA and MSE stress measures.

\subsection{Comparison of POF Values Using ASTM and ASME Rules}

Using the effective volumes, POF calculations were performed on the same notch tensile bar reported in last month's work. Figure 22 shows the probability of failure as a function of applied load to the notch tensile bar. The POF calculation used step-wise increases in the uniform mesh density in the finite element model analysis. This was done to determine if mesh size has an effect on the determination of the POF. The mesh is proportional to the number of degrees of freedom reported in the legend - the higher the number of POF, the smaller the mesh size. There is no indication of mesh size dependence for the POF calculation. An additional test was done using the mesh for the effective volume calculation where the mesh was concentrated at the peak stress and not uniformly distributed. The same results were obtained. So, not only is there no mesh size dependence, there is no dependence on meshing stress concentration. These results differ from the effective volume calculation where mesh density will influence the effective volume. The red trace in Figure 22 is the POF determined effective volume for PIA and the blue trace is the POF determined effective volume for MSE. Numbers in the legend are the numbers of the degree of freedom. Increasing DOF represents smaller mesh sizes. The difference between the curves is due to the improved representation of the multiaxial stress state in the MSE effective stress.

Figure 23 is a plot of POF calculation using Weibull weakest link theory as reported in this essay and the method in the current ASME graphite component code. The ASME rule replaces the Weibull scale parameter with the uniaxial characteristic strength in the integral and therefore does not use the effective volume. The characteristic strength obtained from uniaxial tensile tests is not representative of the specimen size or stress state in the notch bar. The difference between the two POF calculations is significant. 


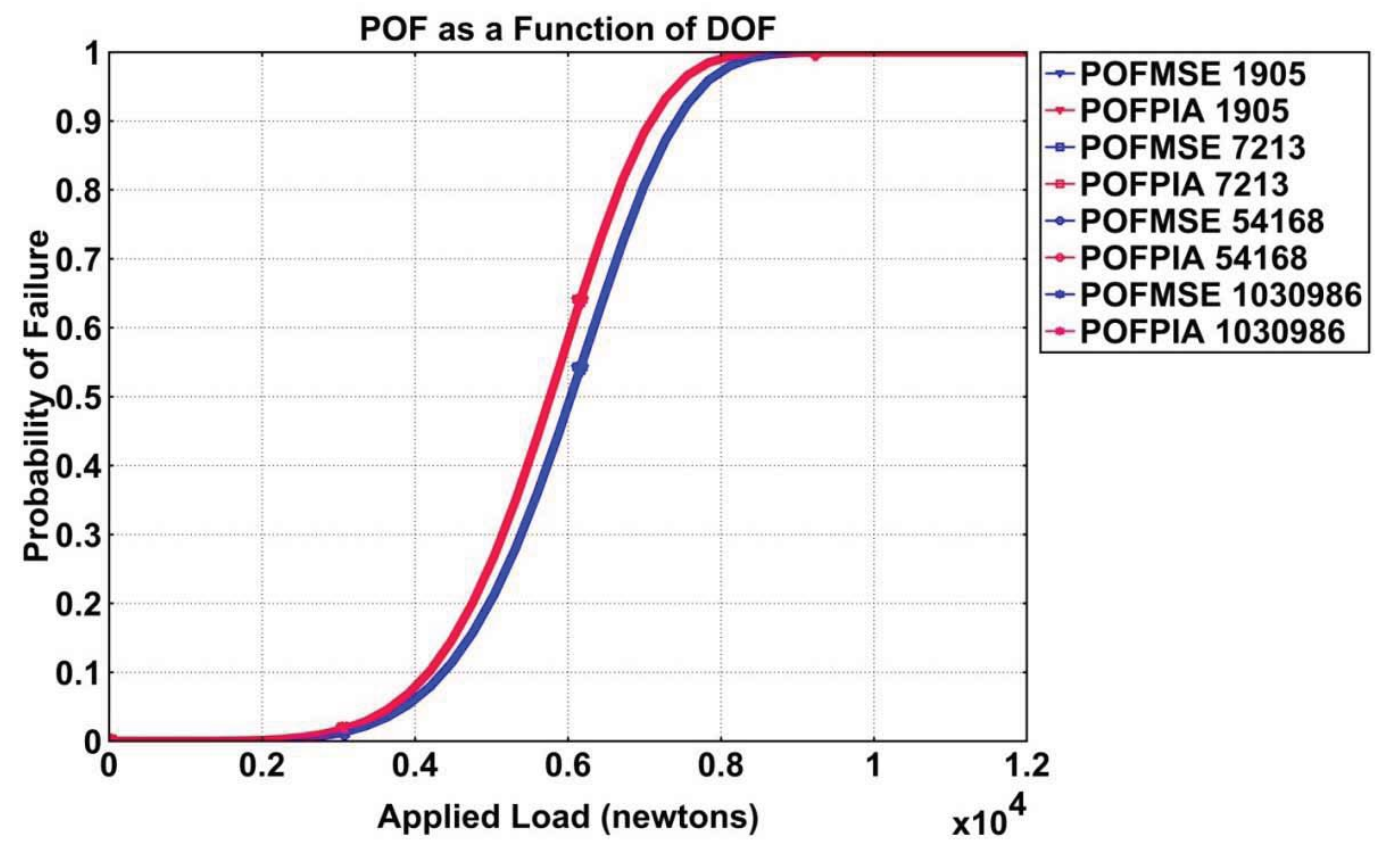

Figure 22. POF calculation for the notch tensile bar $(\mathrm{r}=20 \mathrm{~mm})$ as a function of applied load on the bar.

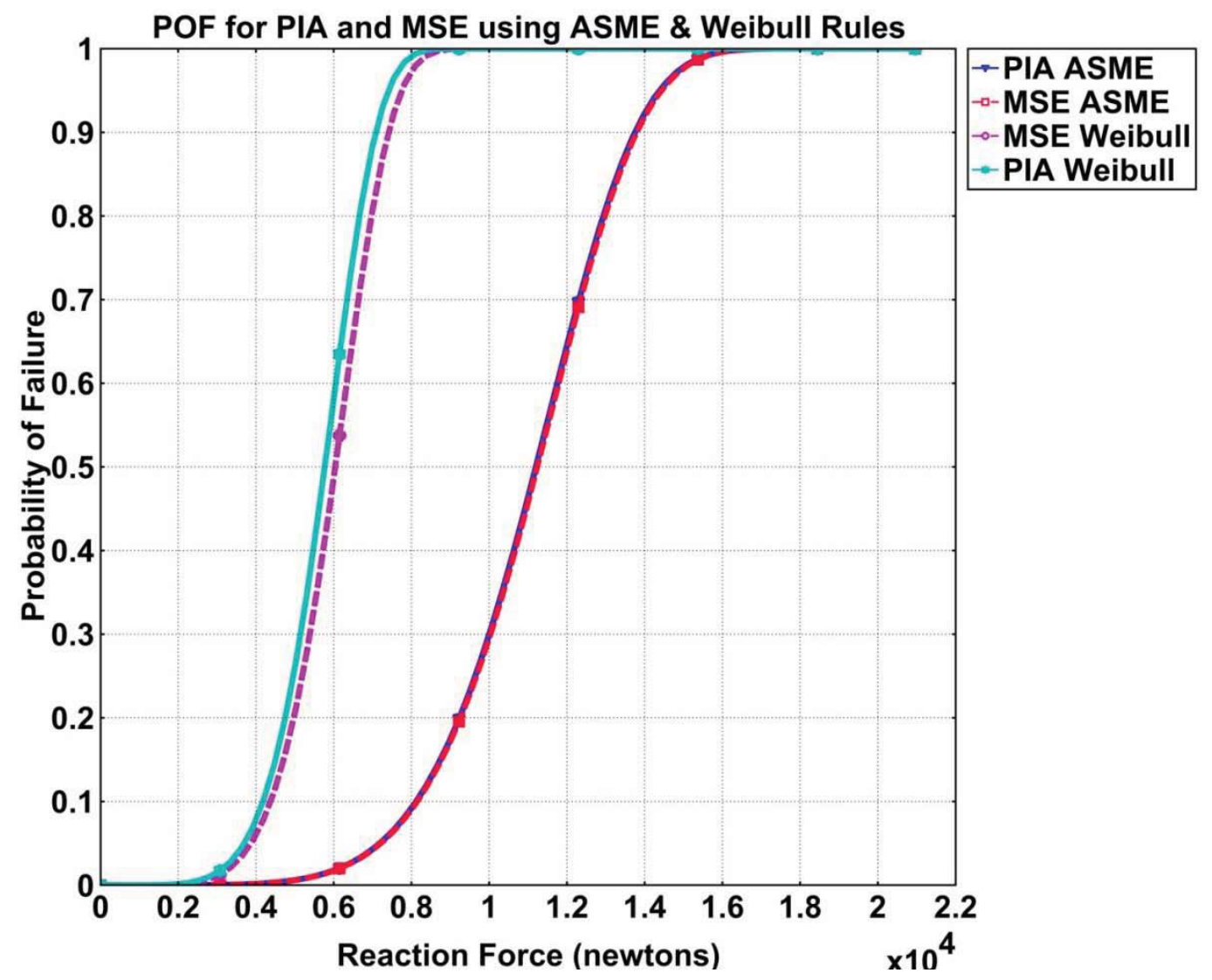

Figure 23. POF calculation as a function of the applied load on the notched tensile bar. 


\section{NUCLEAR ENGINEER AND DESIGN PAPER ON STATISTICAL MODELS FOR NONIRRADIATED GRAPHITE}

A journal paper authored by NASA and INL is published in the Journal of Nuclear Engineering and Design, Vol. 240, pages 1-29. The title of the paper is "Overview of statistical models of fracture for nonirradiated nuclear-graphite." The paper discusses the quasi-brittle nature of graphite and relevant statistical failure models. Various brittle and quasi-brittle material systems are discussed in reference to graphite regarding strength distribution, size effect, multiaxial strength, and damage accumulation. This includes descriptions of the Weibull, Batdorf, and Burchell models as well as models that describe the strength response of composite materials, which involves distributed damage. Consideration is given to the predicted transition between brittle and quasi-brittle damage behavior versus the density of damage (level of disorder) within the material system. The literature indicates that weakest-link-based failure modeling approaches appear to be reasonably robust in that they can be applied to materials that display distributed damage, provided that the level of disorder in the material is not too large. The Weibull distribution is argued to be the most appropriate statistical distribution to model the stochastic strength response of graphite.

\section{REFERENCES}

1. Chris Chamis, "Analysis of the three point-bend test for materials with unequal tension and compression properties," NASA TN D-7572, 1974.

2. ASTM C -1239 -07, "Standard Practice for Reporting Uniaxial Strength Data and Estimating Weibull Distribution Parameters for Advanced Ceramics."

3. ASTM C-1683-08, "Standard Practice for Size Scaling of Tensile Strengths Using Weibull Statistics for Advanced Ceramics."

4. Email from Eric Baker of Connecticut Reserve Technologies "Re: question on determining effective volume," 2/26/2010.

5. Brucker-Foit, et al, "On the Contribution of Notches to the Failure Probability of Ceramic Components," Journal of the European Ceramic Society, Vol. 16, 1996, 1027-1034. 